\title{
CONHECIMENTOS ESPECIALIZADOS SOBRE OS PROBLEMAS DE RENDIMENTO ESCOLAR: UM ESTUDO DE MANUAIS DE PSICOLOGIA E DA REVISTA DE EDUCAÇÃO'
}

DOI: http://dx.doi.org/10.1590/2236-3459/50901

\author{
Ana Laura Godinho Lima \\ Universidade de São Paulo, Brasil.
}

Luciana Maria Viviani

Universidade de São Paulo, Brasil.

\begin{abstract}
Resumo
Neste trabalho efetua-se uma caracterização dos discursos da pedagogia e da psicologia sobre os problemas de rendimento escolar. A análise incide sobre o período de estruturação do sistema público de ensino e de difusão dos princípios da Escola Nova. São analisados artigos da Revista de Educação, também denominada Educação e Escola Nova, e manuais de psicologia educacional destinados à formação docente, publicados nas décadas de 1930 e 1940. A análise baseia-se em textos de Michel Foucault e Dominique Maingueneau sobre o discurso. $O$ exame dos enunciados da psicologia e da educação indica que a melhoria do rendimento escolar era relacionada à possibilidade de produzir conhecimentos científicos sobre o aluno e controlar, rigorosamente, a organização do trabalho escolar, em especial as atividades docentes.

Palavras-chave: rendimento escolar, trabalho docente, revistas pedagógicas, manuais de ensino.
\end{abstract}

\section{EXPERTISE ON THE PROBLEMS RELATED TO SCHOOL PERFORMANCE: A STUDY OF PSYCHOLOGY TEXTBOOKS AND THE JOURNAL OF EDUCATION}

\section{Abstract}

This article presents a depiction of the discourses of pedagogy and psychology on the problems related to school performance. It focuses on the period when the public school system was being structured and when the principles of the New School spread. The article analyses texts published in the Revista de Educação, Journal of Education also called Education and New School, and educational psychology textbooks for teacher education, published in the 1930s and 1940s. The analysis is based on texts by Michel Foucault and Dominique Maingueneau about the speech. The

\footnotetext{
${ }^{1}$ Este trabalho vincula-se a um projeto interinstitucional financiado pelo CNPq. 
examination of the statements of psychology and education indicates that the improvement of school performance was related to the production of scientific knowledge about the student and to the strict control of school work, especially teaching activities.

Key-words: school performance, teaching, pedagogical journals, textbooks.

\title{
CONOCIMIENTOS ESPECIALIZADOS SOBRE LOS PROBLEMAS DE RENDIMIENTO ESCOLAR: UN ESTUDIO DE MANUALES DE PSICOLOGÍA Y DE LA REVISTA DE EDUCAÇÃO
}

\begin{abstract}
Resumen
El trabajo efectúa una caracterización de los discursos de la pedagogía y de la psicología, sobre los problemas de rendimiento escolar. Incide sobre el período de estructuración del sistema público de educación y de difusión de los principios de la Escuela Nueva. Son analizados artículos de la Revista de Educação, también denominada Educação e Escola Nova, y los manuales de psicología de la educación destinados a la formación docente, publicados en las décadas de 1930 e 1940. El análisis se basa en textos de Michel Foucault y de Dominique Maingueneau sobre el discurso. El examen de los enunciados de la psicología y de la educación indica que la mejoría del rendimiento escolar estaba relacionada con la posibilidad de producir conocimientos científicos sobre el alumno y controlar rigurosamente la organización del trabajo escolar, en especial las actividades docentes.

Palabras clave: rendimiento escolar, trabajo docente, revistas pedagógicas, manuales escolares.

\section{CONNAISSANCES SPECIALISEES SUR LES PROBLEMES DE PERFORMANCE A L'ECOLE: UNE ETUDE DES MANUELS DE PSYCHOLOGIE ET DE LA REVUE DE L'ÉDUCATION}

\begin{abstract}
Résumé
Le travail effectue une caractérisation des discours de la pédagogie et de la psychologie sur les problèmes de performance scolaire. II se concentre sur la période de la structuration du système scolaire public et de diffusion des principes de la Nouvelle École. Les articles publiés dans la Revista de Educação, également appelé Educação et Escola Nova, sont analysés ainsi que les manuels de psychologie de l'éducation destiné à la formation des instituteurs, publiés dans les années 1930 et 1940. L'analyse est fondée sur des textes de Michel Foucault et Dominique Maingueneau sur le discours. L'examen de la psychologie et de l'éducation indique que l'amélioration de la performance scolaire était liée à la possibilité de produire des connaissances scientifiques sur l'étudiant et de contrôler strictement l'organisation du travail scolaire, en particulier les activités d'enseignement.

Mots-clé: performance scolaire, travail des enseignants, revues pedagogiques, manuels scolaires.
\end{abstract}




\section{Introdução}

Ste trabalho efetua-se uma análise dos discursos especializados da pedagogia e da psicologia educacional sobre os problemas de rendimento escolar. A análise incide sobre o período de estruturação do sistema público de ensino baseado nas escolas seriadas, de difusão dos princípios da Escola Nova no Brasil e de valorização da psicologia como disciplina central na formação dos professores. Busca-se verificar como a questão das reprovações de estudantes da escola primária se apresentou como um problema da administração escolar e quais as soluções propostas para superar essa dificuldade, especialmente aquelas relacionadas a mudanças do perfil profissional docente. São analisados artigos da Revista de Educação, também denominada Educação e Escola Nova, publicada pela Diretoria Geral da Instrução Pública de São Paulo, e também manuais de psicologia educacional destinados à formação docente, publicados nas décadas de 1930 e 1940. Recorre-se aos escritos de Michel Foucault e Dominique Maingueneau sobre as formações discursivas.

No decorrer do século 19 e primeiras décadas do século 20 ocorreu o processo internacional de difusão da escola de massas, ou seja, a implantação progressiva dos sistemas de ensino público e obrigatório que pretendiam alcançar toda a população. No Brasil esse foi o momento de organização da escola republicana, cujas instituições emblemáticas foram os grupos escolares e as escolas normais para formar professores. Organizados para permitir o ensino simultâneo, os grupos escolares impuseram como condição de funcionamento a homogeneização das classes, por meio da divisão dos alunos em grupos da mesma idade e com o mesmo nível de conhecimentos. Consequentemente, tornaram necessária a realização rotineira de procedimentos de avaliação das capacidades individuais.

Conforme Jorge Nagle (1997), nos últimos anos do Império houve um amplo debate, que envolveu intelectuais e políticos, acerca da importância da educação para o progresso social. Apesar das diferentes posições em disputa, concordava-se que a República, a democracia e a educação eram elementos imprescindíveis para o avanço do país. Em seguida esse interesse arrefeceu e as iniciativas no campo educacional consistiram em eventos isolados nos primeiros anos do regime republicano. Um pouco mais tarde, a partir de 1915, observou-se um movimento em defesa da educação primária, conduzido ao nível dos Estados, que representou uma retomada parcial dos princípios defendidos anteriormente. Os anos que se seguiram consistiram num período de entusiasmo pela educação, no qual foram levadas a efeito diversas reformas educacionais em estados brasileiros, as quais permitiram ampliar a população escolarizada.

Ainda na década de 1920 a educação tornou-se matéria de especialistas, surgiram os profissionais especialmente dedicados ao ensino escolar, anteriormente pensado e conduzido por homens públicos e intelectuais de outras áreas. Nesse período observouse o aumento das publicações que tratavam de questões educacionais, favorecendo a ampliação do conhecimento especializado na área. Além de ampliar o alcance da educação primária, buscou-se, a partir de então, empreender a renovação da escola e dos seus métodos, mediante a apropriação dos novos princípios pedagógicos que se difundiam na Europa e nos Estados Unidos no âmbito do movimento da Escola Nova. Essas novas teorias se disseminaram mundialmente e foram apropriadas pela 
intelectualidade brasileira, de várias formas e com vários níveis de aproximação. $\mathrm{Na}$ década de 1930, os chamados renovadores do ensino obtiveram vantagens em processos de disputa pelo controle do sistema escolar paulista, buscando implementar tais preceitos nas reformas educacionais. Para Marta de Carvalho (2000), seus opositores, ligados ao movimento católico e defensores do ensino particular e diferenciado para os dois sexos, ficaram associados ao ensino tradicional e atrasado, em discurso construído por defensores da Escola Nova. De todo modo, pode-se dizer que para os dois grupos o papel da elite seria formar a identidade nacional e direcionar a população brasileira para uma situação de maior progresso.

A Escola Nova defendia uma revolução copernicana na educação, ao postular que a criança, e não mais o professor, deveria tornar-se o centro da atividade escolar. Em vez de lugar da transmissão às crianças da cultura elaborada pelas gerações precedentes, entedia-se que era preciso transformar a escola em espaço de acolhimento das motivações infantis, onde se proporcionasse oportunidades de observar, agir e experimentar livremente. As atividades e os interesses do aluno passavam a comandar o aprendizado e não mais o ensino de conteúdos definidos pelos adultos e a autoridade do professor. Valorizavam-se, ainda, as atividades cooperativas, visando-se à formação de indivíduos responsáveis e autônomos, capazes de governar a si próprios em uma sociedade democrática.

Para Monarcha (2009), a nova educação escolar buscava se aproximar das regras do método experimental e pretendia renovar as técnicas de ensino mediante a identificação das diferenças individuais e o mapeamento dos processos de desenvolvimento e maturação infantis. Objetivava ressaltar a influência da sociedade no desenvolvimento da personalidade humana mediante a incorporação de conhecimentos sociológicos ao âmbito educativo e buscava incorporar conhecimentos provenientes da psicologia para melhor caracterizar a criança. Criando a demanda por saberes especializados sobre a psicologia infantil, a pedagogia contribuiu para o desenvolvimento dessa disciplina. Como observa Mitsuko Antunes, "a conquista da autonomia pela Psicologia no Brasil teve na Educação um dos mais importantes substratos para sua realização" (2007, p. 63).

Paralelamente à implantação da escola primária republicana criaram-se, em diferentes Estados brasileiros, diversos laboratórios de psicologia experimental para o estudo dos alunos. Em 1906 foi criado o Laboratório de Psicologia Experimental do Pedagogium, no Rio de Janeiro, planejado por Alfred Binet, o prestigiado inventor dos testes de Q.I. na França, e por Manoel Bomfim, que se tornou o diretor do laboratório. No ano de 1914 criou-se o primeiro Gabinete de Antropologia Pedagógica e Psicologia Experimental do Estado de São Paulo, que foi instalado na Escola Normal da Capital. Deve-se destacar, ainda, o trabalho empreendido por Helena Antipoff, psicóloga russa que foi discípula de Claparède no Laboratório de Psicologia da Universidade de Genebra, que posteriormente se estabeleceu no Brasil e instituiu um Laboratório de Psicologia em Minas Gerais, com o objetivo de subsidiar as ações daquele estado no campo educacional. Essa psicóloga também se dedicou à educação das crianças deficientes e fundou a Sociedade Pestalozzi de Belo Horizonte, em 1932, destinada a "promover o cuidado das crianças excepcionais e assessorar as professoras de classes especiais dos grupos escolares" (Antipoff, 1937 apud Campos et al., 2002, p. 24). Nesse período, a 
psicologia dedicada à educação empenhava-se no estudo da criança deficiente, supostamente incapaz de aproveitar o ensino regular e na investigação das diferenças individuais entre os alunos. Deve-se notar que os estudos da psicologia sobre as questões educacionais manteve estreita associação com as atividades desenvolvidas nas escolas normais:

\begin{abstract}
A produção das Escolas Normais consistiu, provavelmente, numa das mais importantes contribuições para o estabelecimento da psicologia cientifica no Brasil, quer no âmbito teórico, quer no âmbito da aplicação prática de seus conhecimentos. Sua importância reside também no fato de muitos dos primeiros profissionais da psicologia terem iniciado sua formação nessas escolas e terem sido elas incentivadoras da publicação das primeiras obras específicas de psicologia no país. (Antunes, 2007, p. 75)
\end{abstract}

Os ideais de inovação e eficiência educacional que circulavam no país nesse momento retomaram a questão dos altos índices de reprovação e evasão escolar, mediante a elaboração de dados diferenciados sobre o cotidiano institucional, como registros e estatísticas escolares. Por meio desses instrumentos uma caracterização considerada mais acurada e legítima do problema do rendimento escolar foi construída. Dados de 1931, publicados na revista Escola Nova, por Lourenço Filho, informavam que nos estabelecimentos de ensino primário estaduais, ou mantidos pelo Estado, a promoção chegava a uma média de $63,85 \%$, sendo os melhores índices encontrados nos grupos escolares $(69,61 \%)$ e os piores nas escolas isoladas rurais $(51,18 \%)$.

Em relação ao trabalho alfabetizante, no primeiro ano, a situação era ainda pior, com as porcentagens de promoção de 53,64, 62,44 e 42,88\%, respectivamente (São Paulo, 1931). A questão das reprovações e também da evasão escolar, que se mostrava agravada nas escolas isoladas e rurais, mobilizou a intelectualidade paulista e de todo o país, que se envolveu na formulação de explicações e soluções para o baixo rendimento do ensino. O processo de escolarização, que se ampliava desde o início do século, deveria se pautar na ciência objetiva, para atender de forma eficiente uma população de crianças cada vez maior e mais heterogênea.

\title{
Considerações metodológicas
}

A análise dos discursos das revistas pedagógicas e dos manuais de psicologia educacional sobre os problemas de aprendizagem baseia-se nos escritos de Michel Foucault e Dominique Maingueneau sobre a análise do discurso. Recorrendo a Foucault, Maingueneau define o discurso como "uma dispersão de textos, cujo modo de inscrição histórica permite definir como um espaço de regularidades enunciativas” (2008, p. 15). Propõe uma modalidade de análise que escapa à alternativa entre a semiótica textual e a hermenêutica histórica, um tratamento que possibilite preservar, simultaneamente, a dimensão linguística e histórica do discurso. Importa considerar, tanto aspectos relativos à forma em que são dados a ler os discursos, quanto as condições históricas que explicam a recorrência de certos enunciados, enquanto outros, ainda que formalmente possíveis, permanecem ausentes, aquém do limiar de formulação.

A modalidade de análise do discurso proposta por Maingueneau apoia-se num conjunto de hipóteses, tais como a de que o interdiscurso precede o discurso, o que exige considerar não apenas um discurso isolado, mas um conjunto de discursos inter- 
relacionados, o que contribui para que se identifique o "sistema de restrições globais" (2008, p. 22) que incide sobre o conjunto. Outra hipótese importante é a de que o discurso deve ser compreendido não apenas como um conjunto de textos, mas como prática discursiva, a qual não se limita à produção escrita, podendo criar enunciados pictóricos, musicais, etc. O autor entende que a análise não precisa, nem deve estabelecer uma dissociação entre práticas discursivas e outras práticas, pelo contrário, a possibilidade de perceber correspondências entre essas práticas e outras, sem que se perca a especificidade de cada conjunto, permite o aprofundamento de sua compreensão histórica.

As considerações anteriores têm implicações importantes para esta análise, dentre as quais sobressai a exigência de se examinar o conjunto de todos os artigos sobre o tema publicados no periódico selecionado para análise, ao longo da década de 1930 e 1940, assim como diversos manuais de psicologia educacional em conjunto, para que se possa caracterizar o interdiscurso no âmbito do qual cada texto pode ser compreendido. Segundo Maingueneau, "a análise do discurso supõe a colocação conjunta de vários textos, dado que a organização do texto tomado isoladamente não pode remeter senão a si mesmo (estrutura fechada) ou à língua (estrutura infinita)" (2008, p. 21). É a análise de um conjunto de textos que permite identificar as diferenças entre os livros, mas também as suas regularidades, incluindo a recorrência de enunciados e ainda os silêncios eloquentes, que sinalizam as restrições que se impõem a esses discursos.

O estudo da imprensa de educação e ensino, aqui elencado como procedimento de pesquisa, tem sido considerado por muitos autores como uma vertente bastante profícua para a história da educação. Segundo António Nóvoa (1997), tais investigações podem elucidar as multiplicidades do processo educativo, tanto no que se refere a aspectos internos dos processos de ensino, programas e cursos, quanto à atuação das famílias e outros fatores de socialização de estudantes. Por outro lado, os textos criados para a imprensa, por terem uma característica efêmera e frequentemente reativa a ocorrências cotidianas, de teor normativo e político, revelam "reflexões muito próximas do acontecimento, que permitem construir uma ligação entre as orientações emanadas do Estado e as práticas efetivas na sala de aula" (Nóvoa, 1997, p. 13).

Para Denice Catani e Cynthia Sousa (1999), pode-se estudar os periódicos educacionais de duas formas: por meio do estudo do próprio impresso, seu ciclo de vida, temas abordados, levantamento de editores, autores e leitores, o que pode elucidar questões das práticas e disciplinas escolares, e mesmo processos de ensino ou pelo estudo dos periódicos como "núcleo informativo, enquanto suas características explicitam modos de construir e divulgar o discurso legítimo sobre as questões de ensino e o conjunto de prescrições ou recomendações sobre formas ideais de realizar o trabalho docente" (p. 11).

A opção pelo período e pelo periódico citados resultou de um levantamento inicial abrangendo uma série de títulos publicados pelos órgãos oficiais de ensino do Estado de São Paulo, como A Eschola Publica (1895-1897), a Revista de Ensino (1902-1918), Revista da Sociedade de Educação (1923-1924) e Revista Escolar (1925-1927). Nessa primeira verificação notou-se a baixa frequência de discussões a respeito de questões relativas à repetência escolar, tema deste estudo, mesmo considerando outras possíveis denominações ou abordagens correlatas. Na década de 1930 esse assunto se 
apresentava seguidamente nas discussões dos periódicos oficiais, enquanto na década seguinte foi encontrada uma menor frequência para esses tópicos. Desta forma, foram selecionados para compor o conjunto de fontes deste estudo 38 artigos publicados de 1931 a 1939, na Escola Nova (sete artigos) e Revista de Educação (31 artigos) ${ }^{2}$; e 10 textos apresentados pela revista no período de 1940 a 1951.

A análise dos manuais de psicologia destinados à formação dos professores, neste trabalho, pretende ampliar a compreensão sobre os modos como os conhecimentos especializados dessa disciplina foram mobilizados na tentativa de elucidar os problemas de rendimento escolar e auxiliar os professores em seu enfrentamento. Optou-se pelo exame dos compêndios empregados nas escolas normais em vez das obras dos grandes psicologistas e educadores sobre as dificuldades de aprendizagem em função do objetivo de compreender os modos de transmissão das ideias desses teóricos aos docentes em formação. Além disso, entende-se que os manuais permitem verificar como se procurou, a partir das teorias, formular explicações sobre as dificuldades de aprendizagem e recomendações sobre como os professores deveriam agir em relação a esse problema.

Em função de seus propósitos didáticos, os manuais se propunham a intermediar a relação entre as teorias psicológicas e os futuros professores, oferecendo-lhes uma leitura interessada em buscar, na teoria, elementos que permitissem orientar a prática docente. Sendo assim, oferecem subsídios para a compreensão de uma modalidade discursiva específica, aquela que pretende criar pontes entre a teoria e a prática. Por isso mesmo entende-se que os manuais constituem fontes privilegiadas para a apreensão das relações entre os conhecimentos especializados da psicologia e as orientações oferecidas aos professores sobre os modos de entender e lidar com os alunos que não conseguiam aprender (Silva, 2005).

A caracterização dos enunciados sobre os problemas de rendimento escolar presentes no discurso da psicologia baseiam-se nos seguintes manuais: Noções de psychologia aplicadas à educação (1931), de lago Pimentel, professor de psicologia educacional na Escola Normal Modelo de Belo Horizonte; Psicologia (1934), de Plínio Olinto, psiquiatra da assistência a psicopatas e professor de psicologia no Instituto de Educação do Rio de Janeiro; Psicologia educacional (1936), de Nelson Cunha de Azevedo, professor-chefe na Escola Normal Santa Rita, em São Paulo; Psicologia educacional (1943), de Justino Mendes, professor de psicologia da Faculdade de Filosofia, Ciências e Letras Santo Tomaz de Aquino, em Uberaba; Noções de psicologia aplicada à educação (1947), de José de Almeida, professor de psicologia infantil na Escola Normal Oficial de Ouro Fino; Compêndio de psicologia: problemas de psicologia educacional (1949), de Onofre de Arruda Penteado Junior, docente da Faculdade de Filosofia, Ciências e Letras da Universidade de São Paulo.

É possível observar uma estrutura comum aos manuais de psicologia aqui considerados, embora haja variações na forma de organizar o conteúdo. Tipicamente, identifica-se um capítulo inicial dedicado a uma apresentação da psicologia. Os capítulos seguintes são dedicados ao exame de aspectos específicos da psicologia da criança:

\footnotetext{
${ }^{2}$ A revista Educação (1927-1930), publicada pela Diretoria Geral da Instrução Pública de São Paulo e da Sociedade de Educação de São Paulo circulou depois como Escola Nova (1930 e 1931), com volumes temáticos. Voltou para o título inicial em 1931 e 1932 e a partir desse ano até 1943 circulou com o nome Revista de Educação. De 1944 a 1951 retomou o título Educação, voltando depois à denominação Revista de Educação até o término da publicação em 1961.
} 
inteligência, motivação, percepção, linguagem, caráter, etc. O capítulo final é, geralmente, dedicado ao estudo da personalidade, definida como síntese dos elementos analisados anteriormente. As questões relativas aos problemas de rendimento escolar não são objetos de um capítulo específico, mas encontram-se dispersas nas páginas dos compêndios, o que exigiu a sua busca em outras partes da matéria. As considerações apresentadas a seguir foram feitas a partir da leitura de capítulos referentes à inteligência; às crianças anormais, retardadas ou problema e de capítulos que abordam de problemas que podem afetar o aproveitamento escolar do aluno, tais como a fadiga, a preguiça, o sentimento de inferioridade. Nem todos os manuais examinam todos os tópicos mencionados, o que dificulta a realização de comparações entre as maneiras encontradas pelos diferentes autores para tratar de cada um dos temas abordados. Sendo assim, busca-se chamar atenção para os aspectos recorrentes, tendo em vista oferecer uma caracterização desse conjunto de textos da psicologia educacional sobre o tema.

\section{O estudo científico do aluno como forma de enfrentar os problemas de rendimento escolar}

Nos manuais de psicologia examinados a inteligência era, frequentemente, definida como poder de adaptação, como um recurso que o indivíduo mobilizava sempre que se encontrava diante de um problema que não podia ser resolvido por meio de reações automáticas (Almeida, 1947; Penteado Junior, 1949). Essa concepção de inteligência baseava-se em Binet, Stern, Claparède, Dewey e Piaget. Segundo José de Almeida, "a inteligência surge, isto é, se revela, quando ao indivíduo se lhe depara um problema, uma nova situação, que não pode ser resolvida com os esquemas instintivos habituais" (1947, p. 162).

A inteligência era compreendida como algo que os indivíduos possuíam em uma determinada quantidade, que era possível medir e que permanecia estável ao longo da vida. Recorrendo-se aos escritos de Alfred Binet, era comum que se dividisse os alunos considerados pouco inteligentes em dois grupos: os anormais de hospital apresentavam deficiência mental profunda e acreditava-se que eram incapazes de se tornarem independentes, de modo que se recomendava a sua internação em asilos ou hospitais; os anormais de escola eram também designados como débeis mentais, retardados ou atrasados. Esses, embora se mostrassem incapazes de acompanhar o ritmo normal do ensino, podiam ser educados em classes especiais das escolas regulares e preparados para o exercício de ofícios pouco exigentes para o intelecto.

Nessa linha de pensamento, o ortofreniata Norberto S. Pinto, em artigo sobre a assistência aos anormais psíquicos, fez uma detalhada classificação das crianças anormais, a partir de uma primeira separação em educáveis, semi-educáveis e ineducáveis. As escolas para anormais poderiam ser internatos ou semi-internatos, ou então se restringir a classes diferenciais, anexas às escolas públicas. $O$ autor considerava problemática esta última opção, pois apesar de poder aproveitar instalações e materiais das instituições já existentes, não se constituiria em "quadro edificante para o regime escolar, observando-se (muito embora acidental), ao mesmo lado de meninos de inteligência normal, infelizes crianças às quais a natureza negara o precioso dom de um intelecto vigoroso" (Pinto, 1943, p. 85). 
Era comum que essas crianças fossem simultaneamente designadas como instáveis, o que significava que, além da falta de inteligência, manifestavam problemas de comportamento na escola. Estabelecia-se assim uma associação entre retardamento intelectual e imoralidade, o que levava os psicólogos a afirmarem que essas crianças eram não apenas incapazes, mas também perigosas:

Quando pequeninos (os débeis mentais) dão grande trabalho aos pais, são maus exemplos para os irmãos, incomodam os vizinhos; se conseguem penetrar na escola são de lá expulsos após uma série de penalidades e depois de terem pervertido uma classe ou sofrido dos companheiros toda sorte de provações; uma vez adolescentes são ladrões, pederastas, incendiários, envenenadores, prevaricadores, pelo menos caem na malandragem; as mulheres se prostituem, enjeitam os filhos etc. (Olinto, 1931, p. 262)

As explicações para a existência de crianças que não aprendiam conforme o esperado caracterizavam-se pelo determinismo biológico. Em alguns casos, recorria-se à craniometria, que pretendia demonstrar a existência de uma relação entre as medidas do cérebro e a quantidade de inteligência dos indivíduos. Encontram-se nas páginas dos manuais examinados referências a diversos estudos de acordo com os quais o peso do cérebro era maior nos indivíduos das raças civilizadas do que nos povos primitivos. Em alguns casos alertava-se para a presença de estigmas, sinais físicos de degeneração presentes nas crianças anormais. A passagem a seguir apresenta um exemplo da crença de que a incapacidade intelectual manifestava-se no corpo dos indivíduos:

Outra prova é a que resulta da comparação metódica, dos indivíduos pertencentes a raças e a culturas diferentes. Ao passo, com efeito, que, nas sociedades de civilização mais requintada, o peso do cérebro vai, em média, a 1400 gramas, em outras, de civilização mais retardada, como as de alguns selvagens africanos, não excede, em regra, 1000 gramas, ou pouco mais. (Pimentel, 1931, p. 99)

Mais frequentemente, contudo, explicavam-se as deficiências por meio da suposição de que a inteligência era um atributo inato e fixo. Penteado Junior, por exemplo, em 1949, questionava o valor das características físicas exteriores como indicativas da incapacidade mental e afirmava que os estudos que buscavam estabelecer essas relações já haviam sido desacreditados, tendo sido substituídos pelas investigações baseadas nos testes de inteligência, considerados científicos e confiáveis. Mesmo assim, prevalecia o determinismo biológico. Nos manuais publicados na primeira metade do século 20 a deficiência mental era quase sempre percebida como uma característica intrínseca e permanente, atribuída à hereditariedade. Segundo pensava Azevedo,

o problema é complexo e extremamente importante para a raça, porque a debilidade mental é hereditária, o que nos leva a dizer que os débeis mentais transmitem de pais para filhos a tara inelutável. Inelutável porque, nos casos mais profundos, a educação absolutamente nada pode fazer, e embora as escolas especiais para débeis mentais resolvam em parte o problema, não o eliminam, pois, nos bancos em que se sentaram os pais, sentar-se-ão os filhos. (1936, p. 219) 
Conforme o discurso hegemônico, a inteligência era herdada e estabelecia um limite intransponível para os indivíduos, embora alguns autores expressassem o ponto de vista segundo o qual a educação podia oferecer uma contribuição decisiva ao indivíduo, ao promover o desenvolvimento máximo de sua inteligência potencial. Em artigo publicado na Revista de Educação em 1938, Bruno Vollet afirmava que a inteligência era o fator preponderante no aprendizado, mas admitia que haviam outros intervenientes, como a aptidão para as diferentes disciplinas, a aplicação, a atitude mental e o estado de saúde do aluno, além de fatores referentes ao professor, como método, paciência, clareza e outros. Em Psicologia educacional (1943), Justino Mendes expressava a crença de que por meio de "uma educação moral e física bem dirigida pode-se atuar muito eficazmente sobre os males hereditários" (p. 83).

Além do estudo quantitativo da inteligência, por meio da escala métrica de Binet ou da aplicação de outros testes, a psicologia defendia a realização de uma série de outros procedimentos experimentais para a identificação das aptidões especiais dos alunos, as quais expressavam a dimensão qualitativa da inteligência e eram fundamentais para a sua orientação profissional. No compêndio Psicologia educacional (1936), Nelson de Azevedo explicava: "Os testes de aptidão se propõem a avaliar os pontos fracos e fortes da fisionomia mental dos indivíduos, quando se deseja adaptar a Educação às disposições naturais e utilizar os indivíduos para os trabalhos que Ihes estejam mais indicados" (p. 136).

Entendia-se que uma das principais contribuições da psicologia para a educação era a fundamentação científica da orientação profissional que, como se costumava afirmar, prometia por o homem certo no lugar certo, o que significava encaminhar cada estudante para a profissão mais condizente com seus atributos naturais. Imaginava-se que essa providência permitiria conquistar, simultaneamente, o máximo de satisfação pessoal para o empregado e o melhor rendimento possível do seu trabalho. A esse respeito, assim se pronunciou Plínio Olinto, em artigo na Revista de Educação:

Os jovens que não pretendam perambular pelas profissões que não the convem irão por em contribuição os seus recursos corporais e espirituais, num laboratório de orientação profissional, afim de saber de que maneira Ihes será mais facil ganhar o pão de cada dia e de que maneira melhores serviços poderão prestar à sua Patria. (1931, p. 111)

Por meio do estudo científico do aluno, a psicologia prometia oferecer o seu auxílio à superação dos problemas de rendimento escolar. A identificação das características individuais era útil à organização do trabalho na escola porque permitia operar uma série de ajustamentos: possibilidade de alocar adequadamente o indivíduo na instituição e na classe mais indicada para o seu caso; de adaptar o ensino às possibilidades de cada grupo; oportunidade de estudar as aptidões naturais, tendo em vista promover a orientação profissional do estudante, tendo em vista o seu ajustamento social.

\section{A seleção de classes como estratégia para melhorar o rendimento escolar}

Depois de caracterizar os alunos que não aprendiam ou não se comportavam de acordo com as expectativas dos professores e investigar as causas de seus problemas, que recomendações os discursos da psicologia ofereciam para a sua educação? 
Primeiro era preciso discriminar os alunos a partir do estudo psicológico de sua inteligência, de suas aptidões. Para isso, recomendava-se o recurso aos testes de inteligência, especialmente aqueles formulados por Binet, que permitiam identificar as crianças retardadas e estabelecer o nível mental de cada aluno, tendo em vista encaminhá-lo para a modalidade de ensino mais adequada às suas necessidades individuais. Para Lago Pimentel

numerosas têm sido as aplicações recebidas pela escala de Binet. A primeira de todas deveria necessariamente ser aquela para que a escala em verdade foi criada: a seleção de crianças cuja inteligência deficiente exige que sejam colocadas em ambiente apropriado à sua educação. As vantagens daí resultantes para o ensino saltam imediatamente aos olhos. As classes comuns ficam, desse modo, desimpedidas de elementos que Ihes entravam e perturbam gravemente 0 trabalho escolar. Desembaraçados dos companheiros retardados, os alunos normais podem progredir com a eficiência e a rapidez que lhes permite seu desenvolvimento mental. Os retardados, por outro lado, que se achavam paralisados pela incapacidade de acompanhar os outros em sua marcha natural, uma vez separados e submetidos a processos pedagógicos adequados, soem, não raramente, dar mostras de certas aptidões aproveitáveis, que, de outro modo, jamais chamariam a atenção. (1931, p. 26)

Conforme os especialistas, as crianças anormais deveriam ser impedidas de se matricular nas escolas regulares e encaminhadas para escolas especiais. Por outro lado, avaliava-se que os casos menos profundos de deficiência mental poderiam ser atendidos em classes especiais das escolas comuns. Crianças que apresentassem rendimento apenas ligeiramente inferior à média seriam reunidas em classes selecionadas de acordo com o nível mental, nas quais o ensino seria ajustado às suas possibilidades reduzidas.

As recomendações para a superação dos problemas de rendimento escolar, presentes nos manuais de psicologia destinados à formação de professores, baseavamse em três princípios fundamentais: estudo científico do aluno, tendo em vista a identificação do seu nível de inteligência e de suas aptidões naturais; seleção das turmas, de acordo com o critério da capacidade mental, e ajustamento do ensino às possibilidades de cada grupo de alunos.

O discurso sobre a seleção de classes também esteve bastante frequente nos artigos do periódico em estudo, como explicitado no excerto abaixo:

Uma classe composta de material humano mal classificado diminui sensivelmente a sua porcentagem de alfabetização, prejudicando os alunos em geral, segundo o critério adotado pelo professor. Além disso, [...] aumentam as despesas para os cofres públicos. Há crianças que repetem duas, três e até quatro vezes uma classe, e estas, embora consideradas de baixo nível mental ou anormais, deveriam ser classificadas como tais, ocupando uma classe à parte ou especial na escola, o que nem sempre é possível e, especialmente no interior. [...] os alunos, não vencendo paralelamente os seus estudos, tornam-se indisciplinados fatalmente. (Amorim, 1937, p. 111) 
Verificou-se, no entanto, que a justificativa para tal seleção apareceu em poucos artigos, sendo que, em sua maioria, essa necessidade estava implícita, havendo apenas a defesa dos testes $A B C$ como a melhor forma de efetuar essa seleção. Ao longo de toda a década de 1930 foram publicados artigos que reforçaram a pertinência da seleção de classes por meio desses testes, incluindo aqueles apresentados na seção Através de revistas e jornais, que trazia publicações veiculadas em periódicos nacionais e internacionais, especialmente dos Estados Unidos.

Nesse mesmo sentido, pode-se citar o volume temático de Escola Nova dedicado aos testes, publicado em 1931 e organizado por Lourenço Filho, então diretor de Ensino de São Paulo. O problema do rendimento do ensino, anteriormente atribuído quase que exclusivamente a questões didáticas deveria, segundo Lourenço Filho, ser considerado de outra maneira, com o auxílio da ciência e da técnica. $O$ autor menciona a oportunidade de aplicar aos fenômenos sociais, em especial à área da educação, a técnica e a ciência, e assim construir os princípios da pedagogia científica com base em medidas, representadas pelos testes: "o progresso da technica da educação resulta da applicação da medida. Medindo, podemos avaliar com segurança do material, do processo e do effeito" 3 (1931, p. 254; ênfases do autor). Para ele, desta forma, "conhecendo melhor dos elementos humanos, podemos também adaptar os processos, com que queremos modificar, as qualidades e defficiências encontradas" (1931, p. 254). Em várias de suas publicações Lourenço Filho ressaltou as vantagens de utilizar testes para selecionar alunos e classes, como o seu caráter objetivo, impessoal, inequívoco, além da rapidez no diagnóstico e da economia para os cofres públicos. Ressaltava-se, ainda, a possibilidade de avaliar com maior justiça o trabalho do professor para, assim, otimizar a organização do processo de ensino e aprendizagem.

Diretores de grupo escolar, delegados regionais de ensino e outros autores sem função identificada adotaram um discurso semelhante, com explicações sobre as melhores técnicas de aplicação dos testes e justificativas sobre sua importância e efetividade, muitas vezes com a apresentação e análise de dados empíricos levantados em escolas testadas. Seguindo essa tendência, em 1936 houve uma contribuição de autoria de duas professoras que relataram sua experiência de três anos na aplicação dos testes $A B C$ :

Adeptas da seleção dos alunos, collocamo-nos ao lado dos que classificam os tests $A B C$ como o melhor para conseguíl-a, embora reconheçamol-os falliveis. [...] Julgamos o critério da observação insufficiente para dentro de alguns dias nortear a mestra na escolha de crianças fortes, médias e fracas. Demais a observação é feita por pessoas diferentes no modo de julgar e classificar, desiguaes na capacidade e na pratica. (Ferraz e Bolliger, 1936)

A organização das classes segundo tais parâmetros se concretizou em orientação da Comissão Técnica de Ensino Primário para as escolas paulistas no ano de 1946, que optou pela vertente teórica que conferia vantagens à homogeneização das turmas, a despeito de reconhecer a existência de abordagens contrárias ao processo de seleção de classes. A argumentação baseava-se no fato de que

${ }^{3}$ Nas citações foi mantida a grafia original. Hist. Educ. [Online] Porto Alegre v. 19 ก. 46 Maio/ago., 2015 p. $93-112$ 
nossas escolas, mercê de circunstâncias várias, se tem visto na contingência de dar maior relevo à iniciação das técnicas fundamentais da aprendizagem do que, realmente, a uma obra de educação integral. Por isso, o rendimento escolar é medido mais pelo seu resultado em termos de aprendizado do que pelo controle da aquisição de hábitos e atitudes desejáveis em situações reais de vida. (Comissão Técnica, 1946, p. 207)

O exame dos manuais de psicologia e dos artigos da Revista de Educação, publicados nas décadas de 1930 e 1940, evidenciam que a classificação das inteligências das crianças, a homogeneização das turmas segundo o nível mental dos alunos e o ajustamento do ensino às possibilidades de cada classe estavam entre as providências mais indicadas pelos educadores e psicólogos para a superação dos problemas de rendimento escolar. Imaginava-se que esse modo de organização do trabalho escolar permitiria controlar melhor os resultados do ensino e acompanhar com mais segurança $o$ progresso dos alunos. Tendo em vista os mesmos objetivos, os especialistas elaboraram ainda uma série de considerações sobre a questão da subjetividade dos professores e seus efeitos na educação.

\section{A subjetividade do trabalho docente como empecilho ao bom rendimento escolar}

Assim como Replogle, diretor de Educação das Escolas Adventistas do Sul do Brasil, muitos outros autores, que publicaram seus textos na Revista de Educação, associaram o rendimento escolar à capacidade de trabalho dos professores e vislumbraram a possibilidade de avaliar essas práticas e também de torná-las mais eficientes. Frequentemente apareceram críticas à atuação docente, seguidas de expectativas de procedimentos considerados ideais e de orientações para o cotidiano escolar.

Vários autores comentaram que os professores tinham dificuldades em realizar a seleção classes de maneira eficiente. A grande subjetividade atribuída ao trabalho do professor primário teria uma interferência negativa em todo o processo de ensino e aprendizagem, inclusive nas taxas de reprovação escolar. Essa subjetividade estaria manifesta nas atividades de observação e de avaliação dos estudantes, poderia e deveria ser superada por novos procedimentos técnicos constituintes da pedagogia científica, fossem testes psicológicos, como os testes $A B C$, ou testes pedagógicos, também chamados de testes de escolaridade ou provas objetivas, para medir o aprendizado dos estudantes nas várias matérias.

Brisolla (1936), diretor do $1^{\circ}$ Grupo Escolar de Baurú e autor de um artigo da Revista de Educação, entendia que a seleção que todo professor realizava no início do primeiro ano era bastante imperfeita, com trocas de turmas, considerando a turma $\mathrm{A}$ como $\mathrm{B}$, a mais forte como a mais fraca, etc. Como o diretor não teria tempo de fiscalizar esse processo a contento, seria necessário adotar os testes ABC. Já Renato Penteado (1938), diretor do Grupo Escolar Dr. Almeida Ferreiro, de Espírito Santo do Pinhal, criticou a seleção empírica que muitos professores realizavam no início do primeiro ano. Eles separavam os repetentes em uma classe considerada forte e formavam, com os alunos novos, as classes médias e fracas, mediante a observação e informação dos professores. $O$ autor ponderou que nem sempre os repetentes poderiam ser considerados fortes e os alunos novos, médios e fracos. Por outro lado, tal classificação seria realizada em relação 
a cada classe e não em relação a todos os alunos da unidade escolar, como deveria ser feito. Por fim, critica a seleção baseada em critérios subjetivos de cada professora já que "é sabido que esse critério varia, até na mesma pessoa, conforme sua disposição de ânimo no momento, quanto mais de um para outro examinador" (p. 61).

Nos manuais analisados essa questão também se faz notar, ainda que de forma menos frequente. Entre os livros analisados, o trecho abaixo traz orientações e cuidados a serem tomados no contato do examinador com a criança, durante a aplicação de testes psicológicos, em que a presença do professor ou dos pais poderia ser um fator de dificuldade:

O examinador estará a sós com a criança. Se isto não for possível, porque se deva operar deante do mestre, ou dos pais da criança, ter-se-á o cuidado de explicar-lhes antecipadamente que devem permanecer em silêncio sem auxiliar ou emitir juízos. Os assistentes deverão compor fisionomia benevolente, aparentando indiferença. (Azevedo, 1936, p. 131)

Outra menção aparece no manual Noções de psicologia aplicada à educação, de José de Almeida, quando comenta o uso dos inquéritos na realização de avaliações psicológicas. Eram questionários que poderiam ser aplicados individualmente, quando os alunos seriam entrevistados, ou coletivamente, por meio de perguntas escritas para que os alunos respondessem. O autor indicava a importância da qualificação dos idealizadores e dos aplicadores dos testes, para que fossem realmente fidedignos: "Toda vez, pois, que os formulários são elaborados por pesquisadores competentes, e as respostas são inteligentemente interpretadas, - esse método dá bons resultados" (Almeida, 1947, p. 44).

Já em relação à avaliação do rendimento escolar, Replogle (1937) defendeu, a adoção de um novo tipo de exame, mediante testes pedagógicos, já que as chamadas provas clássicas envolveriam muitas variáveis, como o estado de espírito do professor e a sua relação pessoal com o aluno:

Resolvi fazer uma experiência. Fiz copias mimeographadas desta prova, e mandei-a a 30 professores, pedindo-lhes que dessem a nota que achassem justa. As notas dadas variaram desde 66 até 100 . Cheguei à conclusão de que as provas clássicas são inadequadas para medir o grau de progresso dos estudantes. (p. 87)

Como encaminhamento para esse problema, ele registra um modelo de exame final de anatomia e fisiologia, que o professor deveria aplicar sem quaisquer alterações.

Quanto à eficiência dos testes, Jacyr Maia, em artigo publicado originalmente na Revista Brasileira de Pedagogia e republicada na Revista de Educação em 1937, na seção Através de revistas, relata um processo de avaliação realizado em 1936, nas escolas primárias da prefeitura do Distrito Federal, em que foram comparadas as três formas mais comuns de medida do rendimento escolar: uma nota dada pelo professor da classe, outra referente a uma prova subjetiva, aplicada por um examinador externo, e um teste. Verificou-se que as notas atribuídas pelos professores foram mais benevolentes, gerando melhores notas, e que os resultados das provas subjetivas foram piores. Após um tratamento estatístico dos resultados, com o cálculo de médias e coeficientes de variação, chegou-se à conclusão de que os testes são os instrumentos mais confiáveis, 
justos e que deveriam ser privilegiados no caso de ser necessária uma escolha entre os três tipos de prova. Nota-se, no artigo, a preocupação em demonstrar a superioridade dos testes de uma maneira objetiva, científica, também mediante uma testagem, com o uso de estatísticas, que poderiam dar às conclusões uma maior legitimidade.

Outra questão frequente é a atribuição de funções para os professores no âmbito da nova pedagogia científica, especialmente em relação à proposta de seleção de classes por meio dos testes $A B C$, em que técnicas, conhecimentos e habilidades mais complexas eram solicitadas.

O conhecimento individual dos alunos, muito valorizado pelos educadores que buscavam estabelecer os parâmetros dessa nova pedagogia, deveria ser obtido sob condições controladas e com base em certos conhecimentos do campo da psicologia, como comenta o autor do manual Compêndio de psicologia:

O estudo individual é mais demorado, mas tem suas vantagens. O estudo pode ser feito com mais cuidado e por pessoa competente. Suponhamos que um grande psicólogo estude um fenômeno psíquico e tome os pacientes individualmente para sua observação. É claro que nem todos poderão fazer o mesmo, porque nem todos terão a mesma competência do grande psicólogo. (Penteado Junior, 1949, p. 18)

$\mathrm{Na}$ apresentação do volume temático já citado de Escola Nova, publicado em 1931, Lourenço Filho conferiu aos professores primários a tarefa de aplicar os testes, o que deveriam fazer sem receio da complexidade do tema e dos princípios que fundamentaram a elaboração do instrumento, brevemente explicitados no artigo. O Serviço de Psicologia Aplicada, recém criado pelo então diretor de Ensino, seria responsável por experimentar e organizar escalas de provas aferidas, escalas de velocidade de leitura e cálculo, testes psicológicos para a indicação de níveis de inteligência e aptidões especiais e mesmo a adaptação de outros testes de inteligência já conhecidos para aplicação nas escolas paulistas.

No mesmo ano, Plínio Olinto (1931) discutiu, tanto em seu livro didático como no artigo publicado no periódico aqui considerado, a participação dos professores no estudo de aptidões e na orientação profissional dos alunos, tema já discutido anteriormente neste texto. A princípio, o autor, em seu livro didático, enaltecia o papel da professora primária:

O estudo das aptidões na orientação profissional é atualmente objeto de cogitações de todos os povos civilizados, onde a luta pela vida é cada vez maior e ninguém melhor do que a professora e a professora primária, que recebe a criança do lar, para encaminhal-a para a vida, ninguém melhor do que ela pode surpreender o despertar das tendências infantis e apresentar o resultado de suas observações como valiosa contribuição ao exame psicológico dos escolares. O magistério primário é, sem duvida alguma, o melhor colaborador do conselheiro profissional. (Olinto, 1931, p. 239)

No entanto, ao desenvolver suas ideias no artigo da Revista de Educação, considerava que, além da colaboração da casa e da escola, a identificação das aptidões e das tendências profissionais só poderiam ser efetivadas por meio de testes realizados com base em saberes técnicos provenientes do campo da Psicologia. 
Já em 1934 Benedicto de Assis considera fundamental a retomada do processo de seleção de alunos e classes, nos moldes estabelecidos por Lourenço Filho, e propõe a organização de um serviço técnico para a aplicação dos testes, com um funcionário e um auxiliar em cada delegacia de ensino. Ele não descarta a possibilidade de o próprio professor primário realizar o teste, mas considera que as medidas mentais só têm valor quando seguem um rígido controle técnico. Esses funcionários poderiam ser os auxiliares do Serviço de Psicologia Aplicada, diretores de grupos escolares e professores responsáveis pelas cadeiras de psicologia e pedagogia das escolas normais. A despesa gerada por essa iniciativa seria amplamente compensada pela economia de recursos que a diminuição das reprovações traria aos cofres públicos (Assis, 1934).

Algum tempo depois o assunto voltou a ser discutido na Revista de Educação pelo professor Guaraciaba Amorim (1937), diretor do $1^{\circ}$ Grupo Escolar de Avaré, ao comentar um tema proposto para debate pela Diretoria de Ensino em reuniões realizadas com diretores e inspetores. $\mathrm{O}$ autor reconheceu que os testes, da maneira como vinham sendo aplicados, apresentavam muitas falhas e que a seleção de classes não poderia ser o único encaminhamento para resolver a questão do rendimento escolar. Citou outros problemas que os professores enfrentavam, como as muitas doenças que acometiam as crianças, em porcentagem superior a $50 \%$, causando incapacidade de atenção, preguiça, indolência e inquietação, um empecilho à dedicação dos mestres. Quanto à aplicação dos testes, Amorim (1937) atribui a não generalização da aplicação dos testes ABC no Estado à inexistência de técnicos devidamente preparados para esse trabalho. Afirmou que qualquer professor poderia aplicar os testes, mas dentro de certas condições: "um professor medianamente intelligente possue uma intelligencia normal e pode tornar-se um technico eficiente, praticando esse trabalho sob rigorosa fiscalização" (Amorim, 1937, p. 110). Concluiu afirmando que as dificuldades do trabalho devem ser enfrentadas e solicitou auxílio técnico do Serviço de Psicologia Aplicada para o enfrentamento de tarefa de tanta responsabilidade.

O discurso sobre a incapacidade dos professores de trabalhar de forma científica, utilizando instrumentos desenvolvidos por técnicos especializados, resultou na indicação de opções para a qualificação docente. A necessidade de estudo dos professores em exercício foi bastante citada como uma alternativa para que estes pudessem realizar uma avaliação mais objetiva de seus alunos. O próprio Amorim (1937) propunha a organização de cursos de férias para os professores se capacitarem como técnicos. Lourenço Filho propunha que os docentes recebessem o auxílio de professores e assistentes de psicologia e pedagogia das escolas normais, que seriam instruídos oportunamente. Aos professores primários o que o autor recomendava era a "leitura e meditação sobre o assumpto. A pequena bibliografia que este fascículo publica poderá prestar-lhes, neste particular, algum auxílio." (Lourenço Filho, 1931, p. 259).

O manual de autoria de lago Pimentel assim definia as condições ideais para avaliar os alunos e os próprios testes:

Quem deseja experimentar uma escala qualquer de testes (e este preceito estende-se também aos testes coletivos), deverá, antes de mais nada, não só estudar muito pormenorizadamente todas as regras da técnica aconselhada pelo autor, como também procurar segui-la com o máximo escrúpulo. Só assim ficará em condições de, estribado nos dados de sua própria experiência, poder julgar a eficiência, ou ineficiência, a perfeição, 
ou imperfeição, as vantagens, ou desvantagens, do teste. Qualquer modificação que se faça, por mais insignificante que pareça, é, com efeito, bastante para modificar os resultados da prova, os quais, falseados pelo investigador inábil, já não poderão ser os mesmos que os apurados pelo autor. (Pimentel, 1931, p. 29)

Nota-se, nos textos em estudo, uma tentativa de incorporar à prática pedagógica procedimentos técnicos de avaliação psicológica e de rendimento dos alunos, com vistas a garantir a eficiência do processo de ensino e aprendizagem. As testagens eram apresentadas como isentas de subjetividade, contanto que o professor seguisse as orientações elaboradas pelos criadores dos instrumentos, ou mesmo aplicasse os testes modelo. Alternativa seria a aplicação dos testes pelos técnicos dos serviços públicos especializados. Para superar sua suposta subjetividade e incapacidade para utilizar os novos procedimentos, os professores deveriam se qualificar por conta própria, no sentido de se equipararem aos técnicos que dominavam os saberes especializados da psicologia escolar, base da pedagogia científica.

\section{Considerações finais}

A análise dos enunciados da psicologia e da educação nas fontes consideradas permite afirmar que a melhoria do rendimento escolar estava relacionada à possibilidade de conhecer e controlar os elementos implicados na educação escolar. Mais precisamente, era preciso produzir conhecimentos científicos sobre o aluno, alvo da ação educativa, e exercer um controle rigoroso sobre a organização do trabalho escolar, em especial as atividades docentes, as quais deveriam adequar-se às condições apresentadas pelas crianças, tendo em vista a obtenção dos resultados de aprendizagem almejados.

Os autores dos textos examinados entendiam que uma das questões centrais a ser enfrentada na escola era a heterogeneidade dos alunos. Constatavam que as crianças apresentavam diferenças individuais de inteligência e de interesses e, portanto, era preciso classificá-las em turmas homogêneas. Desse modo, o ensino poderia ser ajustado o nível intelectual ou grau de maturidade das turmas, favorecendo o rendimento escolar. Nos discursos especializados, essa convicção de que as práticas escolares deveriam ser adaptadas às condições dos alunos traduziu-se ainda em recomendações para que não se aceitassem as crianças consideradas anormais nas escolas comuns. Desnecessário observar que as medidas da inteligência, caso fossem empregadas como recomendavam os autores, funcionariam como verdadeiras profecias auto-realizadoras, ao estabelecer de antemão o limite das conquistas escolares possíveis para cada criança.

Os autores dos manuais de psicologia acreditavam que a escola errava ao impor o mesmo currículo e as mesmas exigências a crianças que apresentavam possibilidades desiguais de aprender. Além das diferenças de inteligência determinadas pelo componente hereditário, em alguns casos considerava-se ainda que os alunos eram afetados por condições de vida desiguais, especialmente em seu meio familiar, as quais também interferiam em suas possibilidades de aprender. Para superar esse problema recomendava-se o estudo do perfil psicológico do aluno, que poderia ser mais ou menos detalhado, levando-se em conta não apenas a quantificação da inteligência, mas também 
a identificação das aptidões naturais. O ideal que se tinha em vista, sem que se chegasse a formular estratégias práticas claras para a sua concretização, era o do ajustamento do ensino às possibilidades dos alunos, considerados individualmente.

Os textos da Revista de Educação/Escola Nova aqui analisados construíram um discurso segundo o qual a subjetividade do trabalho do professor se revestia de um caráter bastante negativo e potencialmente prejudicial ao processo de seleção de classes e de avaliação do rendimento dos alunos. Tal subjetividade, segundo esse discurso, constituía-se em algo plenamente evitável por meio da aplicação dos testes $A B C$ para a formação de classes homogêneas e da realização de testes pedagógicos para avaliar os alunos.

Quanto à figura responsável pela elaboração e aplicação desses testes, há diversidade de discursos nos artigos analisados, com o delineamento de três níveis de atuação profissional. Em primeiro lugar, o papel restrito atribuído aos professores primários, pela falta de condições técnicas para exercer as tarefas complexas propostas pela pedagogia científica. Alguns autores, como Lourenço Filho, confiavam na possibilidade de aplicação dos testes ABC por parte dos professores, de forma bastante simples e mecânica, mas também aparecem outras indicações na revista que põem em dúvida até mesmo essa possibilidade. Segundo esse discurso, a esses professores só restava estudar mais, refletir e tentar se qualificar com o auxílio de estudos autônomos e cursos suplementares ao de formação inicial.

Outros professores, responsáveis por algumas cadeiras das escolas normais, eram considerados mais bem preparados para desempenhar essas tarefas e foram solicitados a ajudar, ainda que não haja informações sobre a sua efetiva participação nesse processo. Por fim, os técnicos do Serviço de Psicologia Aplicada são apresentados como os profissionais mais indicados para trabalhar com questões técnicas, não somente na aplicação dos testes ABC, mas para confeccionar estatísticas com os dados coletados, adaptar testes já existentes e criar instrumentos complementares para conhecer melhor as habilidades e aptidões dos alunos da escola básica.

Objetividade era uma palavra-chave nos discursos especializados sobre os problemas de rendimento escolar. Por um lado, era preciso realizar o estudo científico da capacidade mental ou da maturidade dos alunos, tendo em vista classificá-los a partir de critérios objetivos em grupos homogêneos. Por outro, o recurso às medidas objetivas constituiu-se em forma de homogeneizar os procedimentos de ensino e de delinear padrões de eficiência docente em um momento em que se pretendia ampliar a escolarização básica e formar indivíduos ajustados à cultura da eficiência e do progresso.

A atividade profissional do professor deveria se adequar a esses parâmetros de eficiência e modernidade por meio da ampliação de seus conhecimentos, com predominância dos saberes especializados referentes ao campo da psicologia, que se delineava como importante fundamento da pedagogia científica nas décadas de 1930 e 1940. Além disso, essa ação docente deveria submeter-se à orientação de profissionais técnicos mais capazes e sob a supervisão e comando da administração escolar, representada pela direção da escola e pelos supervisores de ensino. 


\section{Referências}

ALMEIDA, José de. Noções de psicologia aplicada à educação. São Paulo: Companhia Editora Nacional, 1947.

AMORIM, Guaraciaba. Classes selecionadas. Revista de Educação, São Paulo, v. 19-20, 1937, p. 108-112.

ANTUNES, Mitsuko Aparecida Makino. A psicologia no Brasil: leitura histórica sobre sua constituição. São Paulo: Unimarco/Educ, 2007.

ASSIS, Benedicto de. A homogeneização das classes como um dos fatores da racionalização do ensino primário. Revista de Educação, São Paulo, v. 8, n. 8, 1934, p. 71-77.

ASSUNÇÃO, Maria Madalena Silva de. A psicologia educacional e o ensino da paixão, do prazer e da dor (Minas Gerais 1920-1960). Cadernos de História da Educação, Uberlândia, n. 7, 2008, p. 247-261.

AZEVEDO, Nelson Cunha de. Psicologia educacional. São Paulo: Companhia Editora Nacional, 1936.

BRISOLLA, Francisco A. Reprovações: sua origem e causas. Revista de Educação, São Paulo, v. 13-24, 1936, p. 115-120.

CAMPOS, Regina Helena de Freitas; LOURENÇO, Érika; ANTONINI, Isabel Gontijo. Helena Antipoff e a psicologia no Brasil. In CAMPOS, Regina Helena de Freitas (orgs.). Helena Antipoff: textos escolhidos. São Paulo: Casa do Psicólogo; Brasília: Conselho Federal de Psicologia, 2002, p. 13-31.

CARVALHO, Marta M. C. Modernidade pedagógica e modelos de formação docente. São Paulo em Perspectiva, São Paulo, v. 14, n. 1, 2000, p. 111-120.

CATANI, Denice B; SOUSA, Cinthya P. Imprensa periódica educacional paulista (18901996). Catálogo. São Paulo: Plêiade/Finep, 1999.

COMISSÃO Técnica de Ensino Primário. Recomendação n. 1: a organização de classes para o ano letivo de 1946. Educação, v. 35, n. 50-53, 1946, p. 207-210.

FERRAZ, Anna Nogueira; BOLLIGER, Olga. Organização de classes seleccionadas e applicação dos tests ABC. Revista de Educação, São Paulo, v. 15-16, p. 52-55, 1936.

LOURENÇO FILHO, Manoel Bergstrom. Introdução ao estudo da escola nova. São Paulo: Melhoramentos, s.d.

LOURENÇO FILHO, Manoel Bergstrom. Os testes. Escola Nova, São Paulo, v. 2, n. 3-4, 1931, p. 253-259.

MAINGUENEAU, Dominique. Gênese dos discursos. São Paulo: Parábola, 2008.

MENDES, Justino. Psicologia educacional. Juiz de Fora: Lar Católico, 1943.

MONARCHA, Carlos. Brasil arcaico, escola nova: ciência, técnica e utopia nos anos 19201930. São Paulo: Unesp, 2009.

NAGLE, Jorge. A educação na primeira república. In: FAUSTO, Bóris. História geral da civilização brasileira. Rio de Janeiro; São Paulo: Difel, 1977, p. 261-291.

NÓVOA, António. A imprensa de educação e ensino. In: CATANI, Denice Barbara; BASTOS, Maria Helena Camara. Educação em revista: a imprensa periódica e a história da educação. São Paulo: Escrituras, 1997, p. 11-31.

OLINTO, Plinio. Psicologia. Rio de Janeiro: Guanabara, 1934. 
OLINTO, Plínio. Do valor do exame psico-fisiológico na pesquisa das aptidões. Revista de Educação, São Paulo, v. 3, n. 1-2, 1931, p. 109-118.

PENTEADO, R. A. Seleção de classes. Revista de Educação, São Paulo, v. 21-20, 1938, p. 60-62.

PENTEADO JUNIOR, Onofre de Arruda. Compêndio de psicologia: problemas de psicologia educacional. São Paulo: edição do autor, 1949.

PIMENTEL, lago. Noções de psychologia aplicadas à educação. São Paulo: Melhoramentos, 1931.

PINTO, Norberto de S. A aprendizagem e as crianças anormais. Revista de Educação, São Paulo, v. 30, n. 40-41, 1943, p. 84-87.

REPLOGLE, Leon. Novo typo de exames. Revista de Educação, São Paulo, v. 17-18, 1937, p. 87-98.

SÃO PAULO. Estatística escolar de 1930. São Paulo: Diretoria Geral do Ensino, 1931.

SILVA, Vivian Batista da. Saberes em viagem nos manuais pedagógicos: construções da escola em Portugal e no Brasil (1870-1970). São Paulo: USP, 2005. 400f. Tese (doutorado em Educação). Universidade de São Paulo.

TAVARES, Fausto. A ordem e a medida: escola e psicologia em São Paulo (1890-1930). São Paulo: USP, 1995. 229f. Dissertação (mestrado em Educação). Universidade de São Paulo.

ANA LAURA GODINHO LIMA é professora de disciplinas da área de Psicologia da Educação na Faculdade de Educação da Universidade de São Paulo e orientadora credenciada no Programa de Mestrado em Estudos Culturais da Escola de Artes, Ciências e Humanidades da Universidade de São Paulo.

Endereço: Rua Abdo Ambuba, 223/62 - 05725-030 - São Paulo - SP - Brasil.

E-mail: alglima@usp.br.

LUCIANA MARIA VIVIANI é professora da Escola de Artes, Ciências e Humanidades da Universidade de São Paulo. Atua no curso de licenciatura em Ciências da Natureza e no Programa de Pós-Graduação em Estudos Culturais.

Endereço: Rua Conselheiro Brotero, 1030/31 - 01232-010 - São Paulo - SP - Brasil.

E-mail: Iviviani@usp.br.

Recebido em 14 de outubro de 2014.

Aceito em 22 de fevereiro de 2015. 